\title{
Mechanical characteristics of pine biomass of different sizes and shapes
}

\author{
Mateusz Stasiak $^{1} \cdot$ Marek Molenda $^{1} \cdot$ Maciej Bańda $^{1} \cdot$ Joanna Wiącek $^{1} \cdot$ Piotr Parafiniuk $^{1} \cdot$ Aleksander Lisowski $^{3}$. \\ Marek Gancarz ${ }^{1} \cdot$ Ewa Gondek $^{2}$
}

Received: 19 April 2018 / Published online: 3 May 2019

(C) The Author(s) 2019

\begin{abstract}
In the present study, the mechanical properties of granular biomass of pine origin (sawdust, shavings, long shavings and pellets) were determined. The bulk and tapped densities were determined in a cylindrical chamber. The compacted density was measured, and the influence of the moisture content on this quantity was examined in a vane tester. The flowability and strength properties were determined using a direct shear tester (Jenike box) $210 \mathrm{~mm}$ in diameter and standard Schulze ring shear tester. The tests in the Jenike tester complied with the Eurocode 1 procedure for normal pressure $\left(\sigma_{\mathrm{n}}\right)$ of 15 and $30 \mathrm{kPa}$ and speed of shearing of $0.17 \mathrm{~mm} \mathrm{~s}^{-1}$. Ring shear testing was conducted using a Schulze annular shear cell of $195 \mathrm{~mm}$ outer diameter. Tests were performed for 10 and $20 \mathrm{kPa}$ pre-shear $\sigma_{\mathrm{n}}$. A prototype vane tester was constructed for determining the torque, shear strength, and relaxation of a consolidated sample of granular biomass. $\sigma_{\mathrm{n}}$ was exerted by a pneumatic system with a rubber air spring and yoke. The torque and density were measured for moisture content in the range of 10-50\% and for $\sigma_{\mathrm{n}}$ in the range of 5-30 kPa. The torque was observed to be affected by $\sigma_{\mathrm{n}}$ and the moisture content, whereas no relationship between the torque and the rotational speed was observed.
\end{abstract}

\section{Introduction}

Pine tree is one of the most popular and widely available sources of biomass worldwide. Pine biomass in the form of woodchips, shavings/sawdust or densified as briquettes or pellets is widely used as a renewable source of energy (Oniszczuk et al. 2013, 2015). From the physical perspective, it is a granular material of differently shaped and sized particles. The types of shape of biomass particles were presented by Gil et al. (2013). Knowledge of its mechanical properties is necessary for the design and efficient operation of equipment for handling, storage, and processing (Zulfigar

Mateusz Stasiak

mstasiak@ipan.lublin.pl

1 Department of Physical Properties of Plant Materials, Institute of Agrophysics, Polish Academy of Sciences, Doświadczalna Str. 4, 20290 Lublin, Poland

2 Department of Food Engineering and Process Management, Warsaw University of Life Sciences, Nowoursynowska Str. 159C, 02-787 Warsaw, Poland

3 Department of Agricultural and Forest Engineering, Faculty of Production Engineering, Warsaw University of Life Sciences, Nowoursynowska 166, 02-787 Warsaw, Poland et al. 2006; Ganesan et al. 2008; Wu et al. 2011; Gil et al. 2013; Crawford et al. 2016; Oniszczuk et al. 2016). The wide range of practical requirements and extensive literature review concerning the field were presented in previous papers by Stasiak et al. $(2015,2018)$. The bioenergy practice requires information about density, strength parameters, and flowability. The density of granular materials is a very important parameter for numerous practical applications. It exerts a significant effect on the mechanical characteristics of the material and is used for the estimation of the pressure exerted by the granular material against the structure of the bin or silo. It is also necessary for an accurate estimation of the container capacity. With respect to the bulk density, granular biomass is classified as light (with density $<600 \mathrm{~kg}$ / $\mathrm{m}^{3}$ ) (Stasiak et al. 2012).

The strength properties and the methods of determination of granular materials and powders are standardised in design codes. Eurocode 1 (2006) and ASTM D6128-06 (2006) are the standards recommended for determining parameters using a Jenike shear tester. Parameter determination using the ring shear tester should comply with ASTM D6773-02 (2002). These parameters are crucial for estimating the pressures exerted on storage structures by granular materials as well as for the design of installations to assure reliable flow. 
These parameters are also used in numerical modelling and CAD design (Ayuga et al. 2005). For certain materials, flowability is used as a measure of the quality of granular product that influences its end-use value, and its magnitude characterises granular materials as either free flowing, easy flowing, cohesive, or strong cohesive. The theoretical use of strength properties of biomass materials are widely described in previous papers (Stasiak et al. 2015, 2018).

The mechanical properties of granular biomass are strongly influenced by the particle size distribution and moisture content (Ganesan et al. 2008) and were analysed by many researchers (Mattsson and Kofman 2003; Ileleji and Zhou 2008; Littlefield et al. 2011; Wu et al. 2011; Dai and Grace 2011; Miccio et al. 2013; Barletta and Poletto 2013; Gil et al. 2013). A particular description of these attempts can be found in Stasiak et al. (2015).

In the case of granular biomass, no standardised method for determining the strength and flowability is available. Therefore, it is necessary to develop new techniques or introduce methods from other fields. Vane shear test is a potential method for determining the mechanical properties of granular biomass. This method is extensively used for determining the mechanical parameters of a wide range of materials. It is used for a wide range of food, construction, and soil materials (Barnes and Nguyen 2001; ASTM D2573-72 1972). There are also examples of application of such equipment for determining powder and granular parameters. The US Patent 4.181.023 (1980) presented an apparatus for short-test duration for determining the flowability of rubber powder. Measurements performed immediately and after $24 \mathrm{~h}$ of normal compression of the probe were used to calculate the quotient of the torque, which characterises flowability. The vane rheological test was also used to determine biomass properties. Samaniuk et al. $(2011,2015)$ used a vane rheometer to measure the rheological properties of concentrated lignocellulosic biomass and the yield stress of samples of corn stover and switch grass. The shear vane device was used by Amiri et al. (2012) to determine cow manure yield stress. Dai and Grace (2011) presented a mechanism of the blockage of particles in screw feeding and the influence of the biomass properties on this process. The rotating vane method is widely used in rheology for

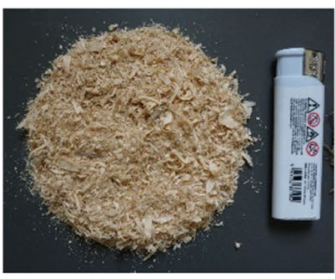

Sawdust

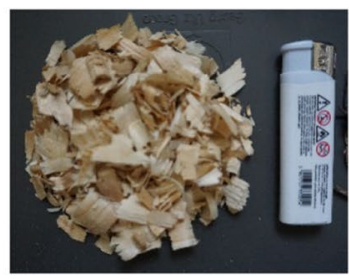

Shavings I

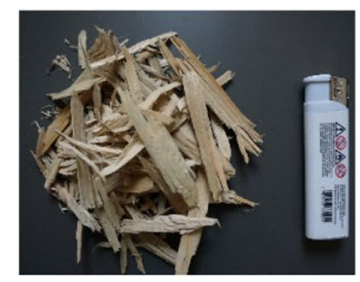

Shavings II

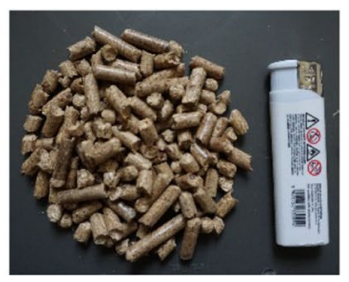

Pellets determining material properties (Barois-Cazanave et al. 1999). Barnes and Nguyen (2001) reviewed the literature regarding technologies where the vane test had been used and gave a series of examples of its use for various materials. Some other practical examples of vane measurements are described in Stasiak et al. (2018).

The literature review reveals that knowledge of the flow properties of granular biomass is still deficient (Zulfigar et al. 2006; Spinelli et al. 2011; Miccio et al. 2011). A significant amount of literature data relates to biomass obtained from different types of sources; however, no data concerning the mechanical characteristics of the different types of biomass obtained from pine tree is available. No summarised paper on the mechanical parameters of pine biomass of different levels of fragmentation is available. In this study, the mechanical, strength and relaxation properties of granular biomass of pine origin (sawdust, shavings, long shavings and pellets) were determined. The paper presents the results of torque measurements obtained from a vane shear tester constructed for determining the strength of consolidated biomass. To date, this tester has been used for examining these types of materials. The measurements could provide information about the stress and torques produced during the emptying of silos with screw feeders. The magnitudes of the torque could permit the estimation of the strength of the material under loads during storage and flow stoppage during discharge. The determination of the shear torque could aid in estimating the loads produced during emptying of the hopper equipped with special emptying equipment such as screw feeder.

\section{Materials}

In this study, four materials of pine origin were selected as the experimental materials. The sawdust and the shavings I and II (different particle sizes) were obtained from a local factory, whereas pine pellets were obtained by a local pellet producer. Images of the experimental materials are presented in Fig. 1.

After the delivery of the materials, sawdust and shavings were dried in thin layers under laboratory conditions. Then,

Fig. 1 Pictures of the different kinds of pine biomass materials 
distilled water was added, and the materials were mixed for $15 \mathrm{~min}$ per hour in a period of $24 \mathrm{~h}$ in a laboratory mixer to obtain the desired moisture contents: 10, 20, 30, 40 and $50 \%$. The levels of moisture content corresponded to those existing in technological practice, wherein biomass under various conditions is delivered, depending on the place of origin, season, and weather. The levels of moisture content are comparable to those in the literature (Nyström and Dahlquist 2004; Miccio et al. 2011). The moisture content was measured by weighing 200-300 g samples before and after $24 \mathrm{~h}$ of drying at $105^{\circ} \mathrm{C}$ in a laboratory oven. The particle size distributions of the sawdust and woodchips are presented in Table 1. In the case of sawdust, sieve analysis was performed, whereas for woodchips, the length of particles was measured with a digital calliper. In both cases, $0.5 \mathrm{~kg}$ of material was examined.

\section{Methods}

Bulk density $\left(\rho_{\mathrm{B}}\right)$ was determined as the ratio between the mass and volume of the material filling a cylindrical chamber, $170 \mathrm{~mm}$ in diameter and $250 \mathrm{~mm}$ high. The tapped density $\left(\rho_{\mathrm{T}}\right)$ was determined using an additional cylinder of height equal to that of the chamber, and the sample was vertically tapped 180 times. As in the case of $\rho_{\mathrm{B}}, \rho_{\mathrm{T}}$ was defined as the mass of the material in the down chamber and its volume.

The strength and flowability of the materials were determined using a direct shear tester, with $210 \mathrm{~mm}$ in diameter. The tests complied with the Eurocode 1 (2006) procedure for normal pressure $\left(\sigma_{\mathrm{n}}\right)$ of 15 and $30 \mathrm{kPa}$ and speed of shearing of $0.17 \mathrm{~mm} \mathrm{~s}^{-1}$. The $\sigma_{\mathrm{n}}$ used in the tests corresponded to the loads in storage silos of approximately $10 \mathrm{~m}$ height that are used in energy plants where the continuity of the energy production must be maintained through co-firing with standard coal fuel.

Based on the experimental curves, the angle of internal friction $\phi$, the effective angle of internal friction $(\delta)$, flowability index $(i)$, and cohesion $(C)$ were determined. The yield locus was determined for two values of $\sigma_{\mathrm{n}}$ (for a nominal value and for half of this value) during shearing. In both cases, the consolidation of the material was conducted with nominal $\sigma_{\mathrm{n}}$. The yield loci were determined from two values of the apparent shear stress $(\tau)$ obtained for two values of $\sigma_{\mathrm{n}}$. The procedure was performed in compliance with Eurocode 1 (2006). Next, Mohr's circles were drawn, which enabled the calculation of the unconfined yield strength, and the major consolidating stress, and $i$ was determined (e.g., Molenda et al. 2006).

Ring shear testing was conducted using a Schulze annular shear cell with an outer diameter of $195 \mathrm{~mm}$ and inner diameter of $100 \mathrm{~mm}$. Tests were performed for $10 \mathrm{kPa}$ and

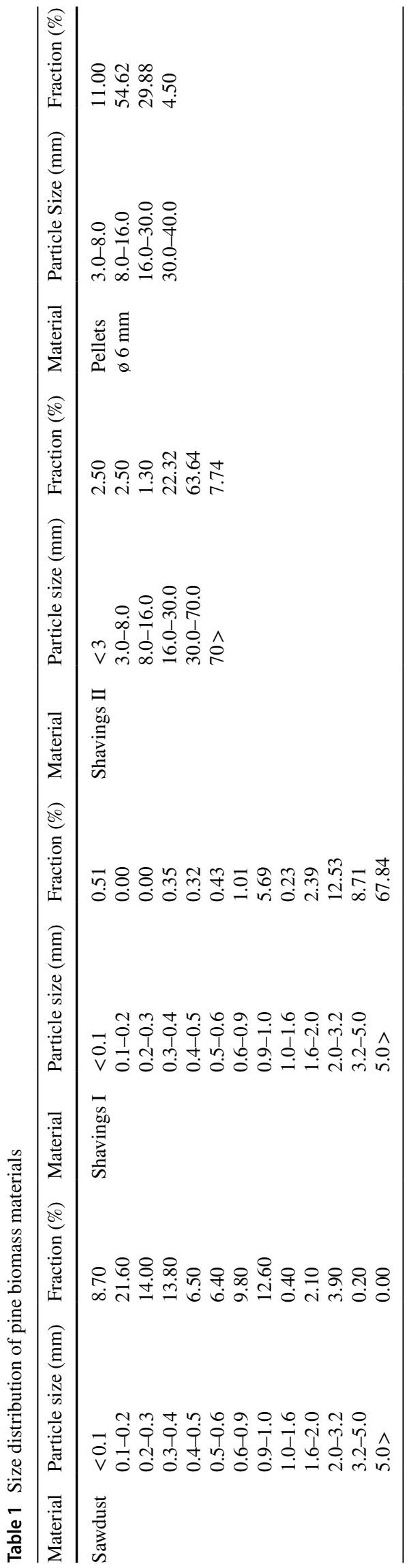


$20 \mathrm{kPa}$ pre-shear pressures and under four levels of $\sigma_{\mathrm{n}}, 2.5$, 5,10 and $2.5 \mathrm{kPa}$ and 5, 10, 20 and $5 \mathrm{kPa}$, respectively. Standard ring shearing procedure was performed, and a set of parameters was determined (Schwedes and Schulze 1990; Schulze 2008). The flow factor (ff) (inverse of flow function) was used to compare the flow properties of different materials. At identical $\sigma_{\mathrm{n}}$, a powder with higher flow function flows more freely (Kamath et al. 1994). Apparent shear stress $(\tau)$, $\delta$, and $\phi$ were also determined.

The measurements of the torque in consolidated cylindrical probes of biomass were taken in a specially constructed vane tester. The apparatus was previously used by Stasiak et al. (2018) for determining the shear behaviour of woodchips. The schematic view of the tester is presented in Fig. 2.

The main part of the tester is a cylindrical chamber, $40 \mathrm{~cm}$ in diameter and $40 \mathrm{~cm}$ high. Inside the chamber, axially, near the bottom, a rotating vane tool $8 \mathrm{~cm}$ high, $12 \mathrm{~cm}$ wide, and featuring four blades is located. The tool is impelled by a gear motor with variable rotation rate. The normal pressure $\left(\sigma_{\mathrm{n}}\right)$ is exerted by the pneumatic system with a rubber air spring and yoke. The rotating vane impeller is assumed to shear only the material placed in the immediate vicinity of the blades. Twelve blades of dimensions equal to those of the blades of the rotating tool are installed on the internal surface of the chamber. The test chamber is supported by the base table and connected with the drive by a claw clutch. The concept of the proposed device is based on a combination of the rheometer and the new system of vertical loading with the yoke and rubber air spring filled with air to the required pressure. The mass of the sample is measured with three load cells supporting the chamber, and the actual height of the sample is measured with three laser sensors to determine the density of the granular biomass. A torque sensor is used to measure the shear load on the rotating vane tool. Tests could be conducted at four rotation rates, 3, 6, 9, and $13 \mathrm{rpm}$, and under four magnitudes of $\sigma_{\mathrm{n}}, 5,10,20$, and $30 \mathrm{kPa}$. The required $\sigma_{\mathrm{n}}$ is generated by a compressor and measured by analogue and digital manometers. The torque vs. time characteristics and other measured parameters are recorded by a data acquisition system. The test procedure includes filling of the chamber, application of $\sigma_{\mathrm{n}}$ and shearing with constant speed. After the maximum torque magnitude is exceeded, the gearmotor is stopped. After a rest period of $\sim 50 \mathrm{~s}$, when the torque decreases to an asymptotic value, the second shearing occurs to attain the maximal value; then, the probe is again relaxed for $\sim 50 \mathrm{~s}$. Subsequently, the sample is unloaded, and the chamber is emptied.

The vane shear tester was also used to determine the density in relation to the normal pressure $\left(\sigma_{\mathrm{n}}\right)$.

All the experiments were performed three times. The ANOVA simple main effect tests were performed with STATISTICA 10, StatSoft Inc. 2011.

\section{Results}

The magnitudes of the bulk density $\left(\rho_{\mathrm{B}}\right)$ and tapped density $\left(\rho_{\mathrm{T}}\right)$ are presented in Table 2. For all the materials, $\rho_{\mathrm{B}}$ is lower than $\rho_{\mathrm{T}}$. As expected, the highest values of the bulk and tapped densities were obtained for pellets. The lowest densities of 56 and $69 \mathrm{~kg} / \mathrm{m}^{3}$, respectively, were obtained

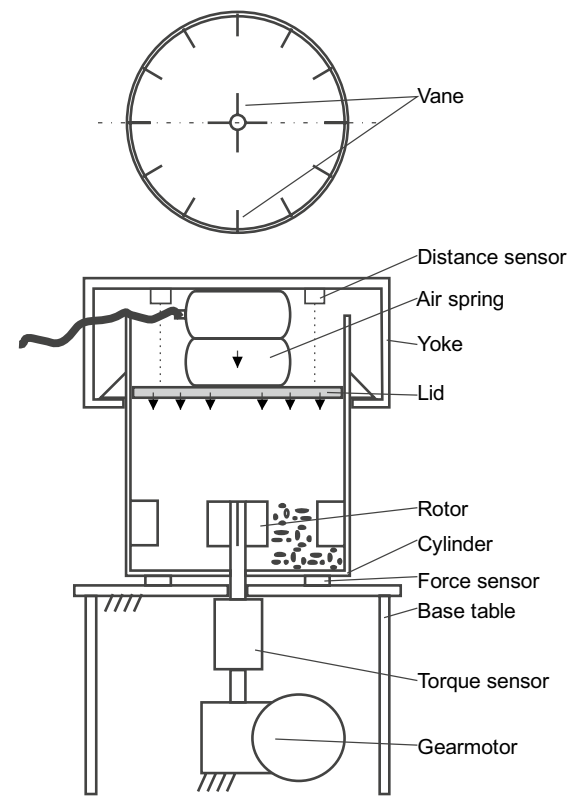

Fig. 2 The schematic of biomass vane torque tester

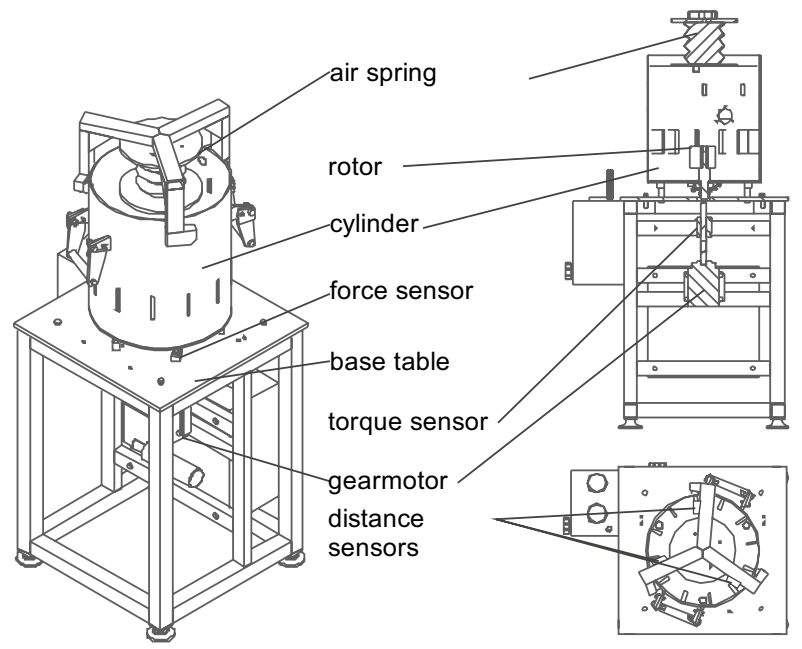


Table 2 Bulk and tapped densities of experimental materials

\begin{tabular}{llllll}
\hline Pine biomass & $\begin{array}{l}\text { Moisture } \\
\text { content } \\
\text { m.c. }(\%)\end{array}$ & $\begin{array}{l}\text { Bulk density } \\
\rho_{\mathrm{B}} \\
\left(\mathrm{kg} / \mathrm{m}^{3}\right)\end{array}$ & $\begin{array}{l}\text { Tapped density } \\
\rho_{\mathrm{T}} \\
\left(\mathrm{kg} / \mathrm{m}^{3}\right)\end{array}$ & $\begin{array}{l}\text { Change } \\
(\%)\end{array}$ & $\begin{array}{l}\text { Housner ratio } \\
\mathrm{HR}\end{array}$ \\
\hline Sawdust & 10 & $143 \pm 4$ & $203 \pm 7$ & 42 & 1.42 \\
Shavings I & 10 & $56 \pm 2$ & $69 \pm 3$ & 23 & 1.23 \\
Shavings II & 10 & $90 \pm 10$ & $142 \pm 16$ & 58 & 1.57 \\
Pellets $\phi 6 \mathrm{~mm}$ & 10 & $732 \pm 10$ & $805 \pm 4$ & 10 & 1.09 \\
\hline
\end{tabular}

for shavings I. The highest compressibility, 1.57, termed as Housner ratio (HR) (Saw et al. 2015), was obtained for shavings II. Such a high HR characterises very low flowability of the material. Significant differences were observed between the two types of shavings. Approximately two times higher magnitudes of the densities were obtained for shavings II. Regardless of the length of the single granules, the shape of the particles significantly influenced the density and compressibility of the granular material, resulting in smaller densities for shavings I composed of arch-shaped granules. The long particles of shavings II formed a regular structure during tapping, providing larger densities. That effect did not occur in shavings I comprising non-regular, arched, and elastic particles.

In the case of pine sawdust, $\rho_{\mathrm{B}}$ was $143 \mathrm{~kg} / \mathrm{m}^{3}$, whereas $\rho_{\mathrm{T}}$ was $203 \mathrm{~kg} / \mathrm{m}^{3}$. For materials stored in silos, it is important to determine the actual density depending on $\sigma_{\mathrm{n}}$; here, the stress acting on the material is simulated by the layers of the stored granules. In this case, the moisture content strongly affected the behaviour of the stored material.

Figure 3 shows the relationships of the whole range of density and moisture content with normal pressure $\sigma_{\mathrm{n}}$ for the tested materials, as measured in the vane shear tester. In the case of the pellets, the relationship between density and $\sigma_{\mathrm{n}}$ is not presented as this material was investigated only for equilibrium moisture content. The densities were also measured for the material probes compressed for $2 \mathrm{~h}$ to examine the time of compressibility $\left(\rho_{2 \mathrm{H}}\right)$. These magnitudes of the densities are plotted on the graphs. For all the materials, a substantial increase in density was observed with an increase in the moisture content. The highest increase in density was obtained for sawdust and shavings I. For these materials, the ANOVA $F$ test $F$ value was 11659 and 12056 , respectively, while for shavings II, it was 8145 . The highest values of density were obtained for sawdust. The density of that material increased from approximately $260 \mathrm{~kg} / \mathrm{m}^{3}$ at $10 \%$ moisture content to approximately $600 \mathrm{~kg} / \mathrm{m}^{3}$ at $60 \%$ moisture content. For samples compressed for $2 \mathrm{~h}$, the densities were marginally higher at $275 \mathrm{~kg} / \mathrm{m}^{3}$ and $616 \mathrm{~kg} / \mathrm{m}^{3}$ for the minimum and maximum moisture contents, respectively.

For shavings I and II, the magnitudes of density were comparable and increased from approximately $90 \mathrm{~kg} / \mathrm{m}^{3}$ for a moisture content of $10 \%$ to approximately $200 \mathrm{~kg} / \mathrm{m}^{3}$ for a moisture content of $60 \%$. At the minimum moisture content, similar time-compression values of density $\left(94 \mathrm{~kg} / \mathrm{m}^{3}\right)$ were obtained for shavings I and II, while at the maximum moisture content, the magnitudes were $209 \mathrm{~kg} / \mathrm{m}^{3}$ and $219 \mathrm{~kg}$ / $\mathrm{m}^{3}$, respectively.

$\sigma_{\mathrm{n}}$ was observed to strongly influence the density magnitudes for sawdust and shavings I and II. The ANOVA $F$ test $F$ value was above 300 for these materials. In the case of pellets, the density marginally increased with an increase in $\sigma_{\mathrm{n}}$, which is a result of the standardised shape of strongly densified particles. The highest magnitudes of density were obtained for pellets and varied from approximately $680 \mathrm{~kg} / \mathrm{m}^{3}$ to $700 \mathrm{~kg} / \mathrm{m}^{3}$. During the compression, the magnitudes increased up to $707 \mathrm{~kg} / \mathrm{m}^{3}$ and $725 \mathrm{~kg} / \mathrm{m}^{3}$ at the minimum and maximum $\sigma_{\mathrm{n}}$, respectively. For sawdust, the density varied from $370 \mathrm{~kg} / \mathrm{m}^{3}$ to $415 \mathrm{~kg} / \mathrm{m}^{3}$. Compression for $2 \mathrm{~h}$ resulted in relatively high increase in density up to $425 \mathrm{~kg} / \mathrm{m}^{3}$ and $465 \mathrm{~kg} / \mathrm{m}^{3}$ for the minimal and maximum $\sigma_{\mathrm{n}}$, respectively. The magnitudes of density, measured for the two types of shavings were comparable and ranged from approximately $140-150 \mathrm{~kg} / \mathrm{m}^{3}$ at the minimum $\sigma_{\mathrm{n}}$ to $160-170 \mathrm{~kg} / \mathrm{m}^{3}$ at the maximum $\sigma_{\mathrm{n}}$.

Figure 4 shows typical experimental plots of apparent shear stress vs. relative displacement for sawdust and pellets obtained from the Jenike shear tester of $210 \mathrm{~mm}$ diameter. A higher repeatability of the experimental results was obtained for sawdust as compared to pellets (Fig. 4a, c) which resulted from the uniform or non-uniform packing of sawdust and larger particles of pellets. The values of the maximum $\tau$ were similar for the two types of materials, ranging from approximately $9 \mathrm{kPa}$ at a normal stress of $15 \mathrm{kPa}$ to approximately $24 \mathrm{kPa}$ at a normal stress of $30 \mathrm{kPa}$.

The experimental results for sawdust, obtained for different moisture contents, were similar (Fig. 4b). The maximum $\tau$ varied from 20 to $24 \mathrm{kPa}$, with the moisture content increasing from 10 to $60 \%$, indicating a marginal effect of the moisture content on the maximum value of $\tau$. This behaviour could be explained by no free water existing and stronger effect of surface state of single particles and structure of the bulk.

Different behaviours of the materials during shearing were observed when being tested in the ring shear tester. The evolutions of $\tau$ with time for sawdust, shavings I and 


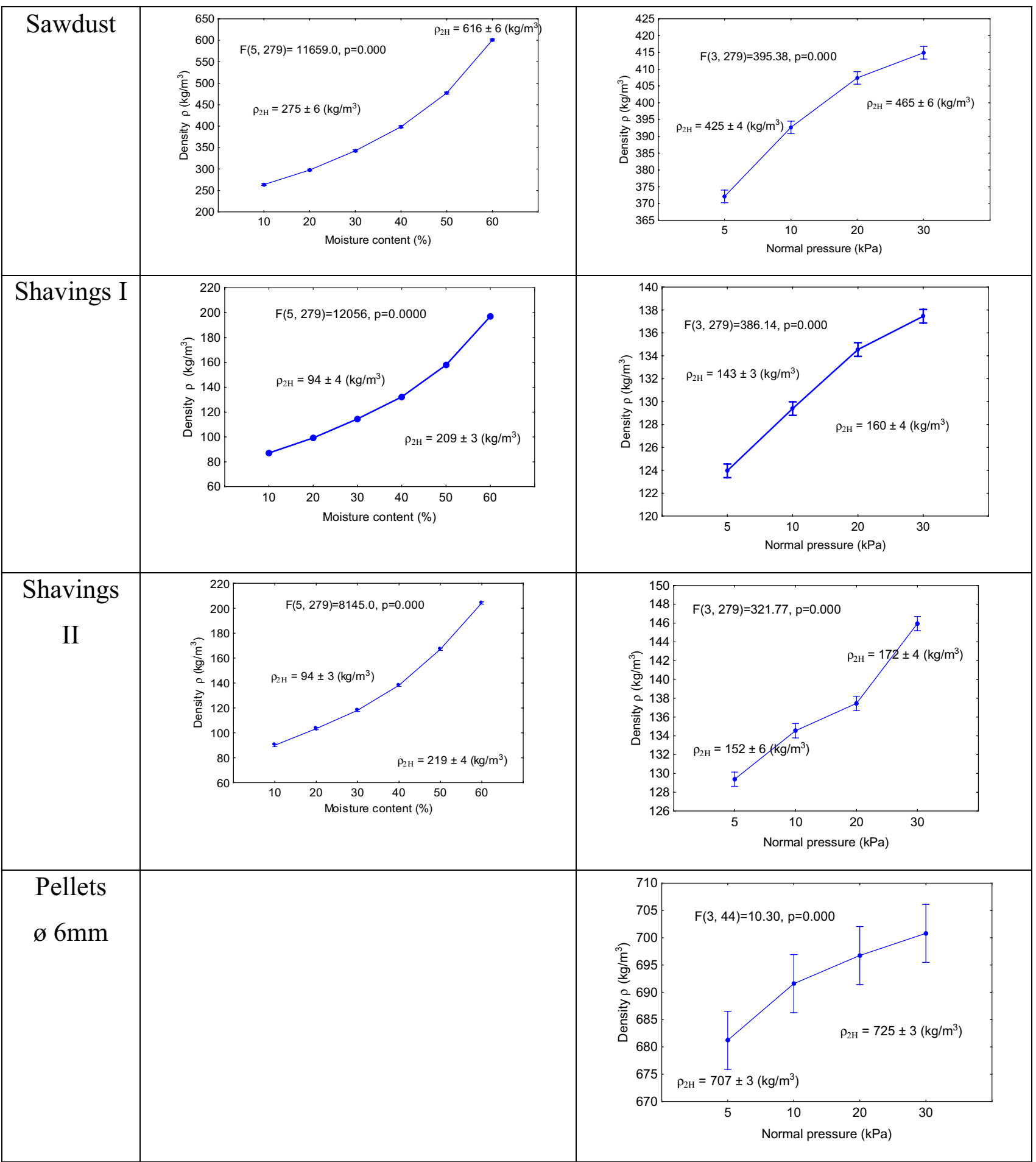

Fig. 3 Relationships of the whole range of density and moisture content with normal pressure, with 95\% confidence intervals of density for tested materials

pellets are presented in Fig. 5. In the case of sawdust, $\tau$ was affected by $\sigma_{\mathrm{n}}$, while moisture content was observed to have no effect on the maximum $\tau$.
For shavings I, both the moisture content and normal pressure $\left(\sigma_{\mathrm{n}}\right)$ were observed to influence $\tau$. Regardless of the magnitude of the consolidation pressure, a decrease in $\tau$ with an increase in moisture content was observed in 

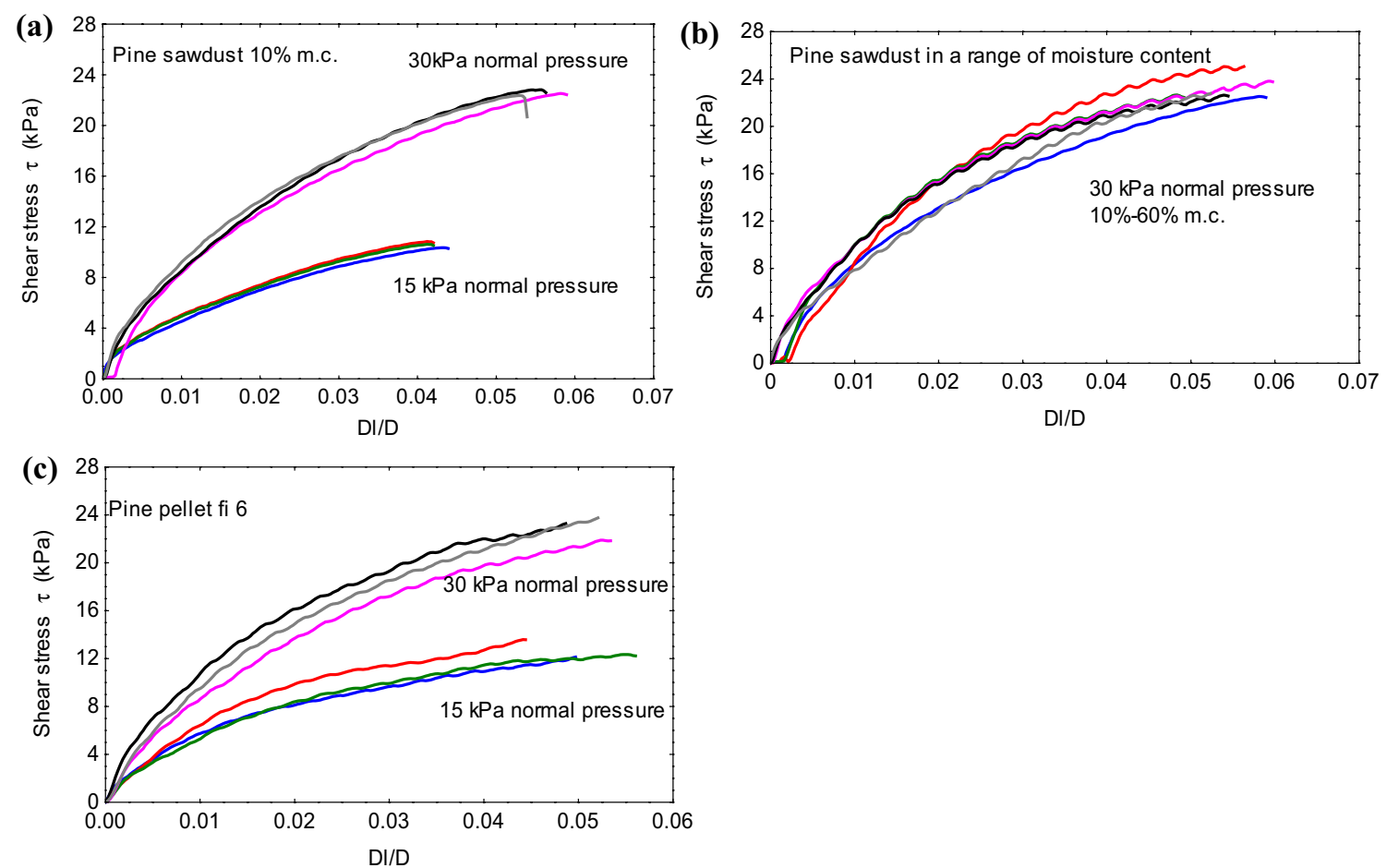

Fig. 4 Individual measurements of apparent shear stress vs. relative displacement for sawdust (a) and pellets (c) for different normal pressures and for sawdust for different moisture contents (b) obtained with Jenike shear tester

that material. These results corroborate the observations reported by Stasiak et al. (2013) for food powders. Significant differences between the magnitudes of $\tau$ for shavings and sawdust were observed, probably owing to differences in shapes of the particles composing these materials. Nonuniformly shaped particles of shavings provided a higher $\tau$ as compared to uniform and fine particles of sawdust. In the case of pellets, the values of $\tau$ were comparable to those determined for sawdust and increased with an increase in the preconsolidation $\sigma_{\mathrm{n}}$.

Tables 3 and 4 present the average values of the mechanical parameters obtained with standard Jenike shear tester and ring shear tester.

The ANOVA test and Statistica software were used to analyse the experimental data. The mechanical parameters for the experimental materials, determined by using the Jenike shear tester and the ring shear tester for different moisture contents and normal pressures $\left(\sigma_{\mathrm{n}}\right)$ are presented in Figs. 6 and 7, respectively. The angles of internal friction, effective angles of internal friction, flowability indexes, and cohesions were obtained from the Jenike shear tester. At the maximum moisture content, the highest magnitude of $\phi$, approximately $35^{\circ}$, was obtained for pine shavings I, whereas the lowest magnitude of the parameter, approximately $28^{\circ}$, was obtained for pine sawdust. For materials composed of the largest particles, i.e., pellets and shavings II, the angles of internal friction were similar and equalled approximately $31^{\circ}-32^{\circ}$. $\phi$ was observed to increase until the moisture content increased to $50 \%$; it decreased with a further increase in the moisture content, owing to the presence of free water in the space between the particles. $\phi$ decreased when $\sigma_{\mathrm{n}}$ increased; however, the differences between the magnitudes of the parameter lay within the range of scatter. A similar effect of the moisture content of material and $\sigma_{\mathrm{n}}$ on $\delta$ was observed in all the materials. Analysis of flowability index $(i)$, allows for characterising sawdust as a free-flowing material, pellets and shavings as free flowing/cohesive materials, and shavings II as cohesive material. In the case of pellets, the largest range of $95 \%$ confidence interval was obtained. For that material, a marginal influence of the moisture content and $\sigma_{\mathrm{n}}$ on $i$ was observed. The highest cohesion (C), approximately $4.5 \mathrm{kPa}$, was obtained for shavings II. For the other materials, the magnitude of $C$ varied from 3 to $3.5 \mathrm{kPa}$. $C$ was observed to be strongly influenced by $\sigma_{\mathrm{n}}$; however, no effect of the moisture content on this parameter was observed.

The ANOVA statistical test results for the data obtained with the ring shear tester are presented in Fig. 7. The automatic procedure of the ring shear tester did not permit the performance of the experiments for shavings II owing to the excessive length of single particles. The highest value of ff was determined for pellets, which characterised this material as free flowing. That result was consistent with the one obtained by using the Jenike shear tester. However, 

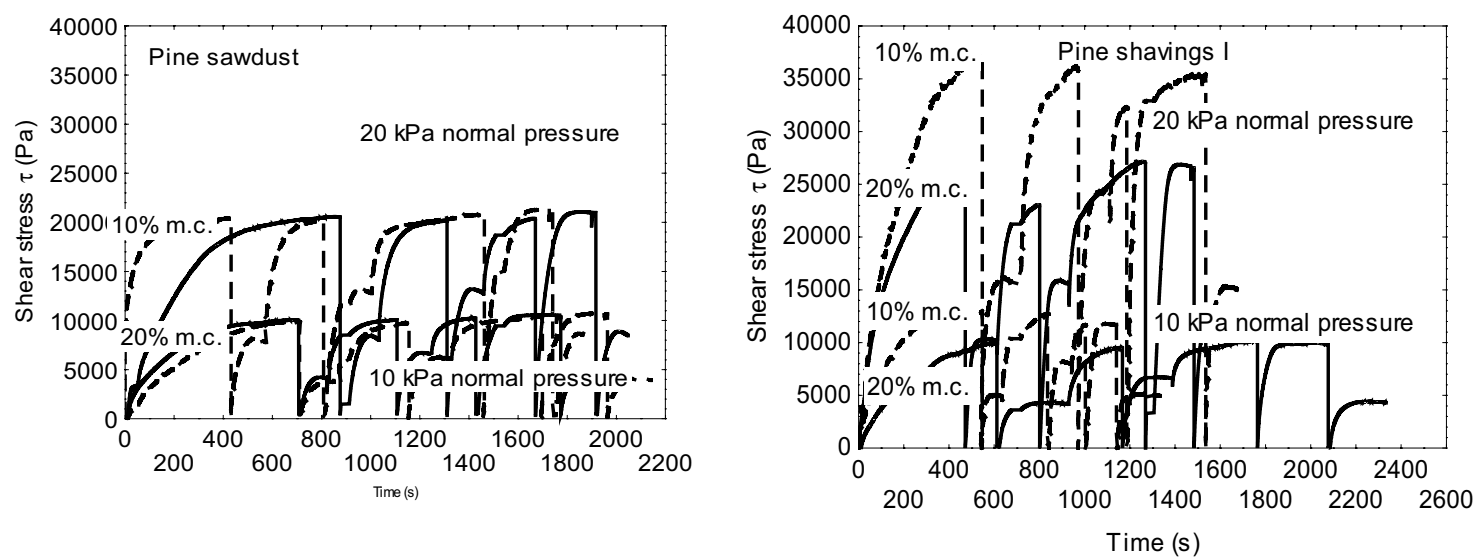

\section{No data for shavings II}

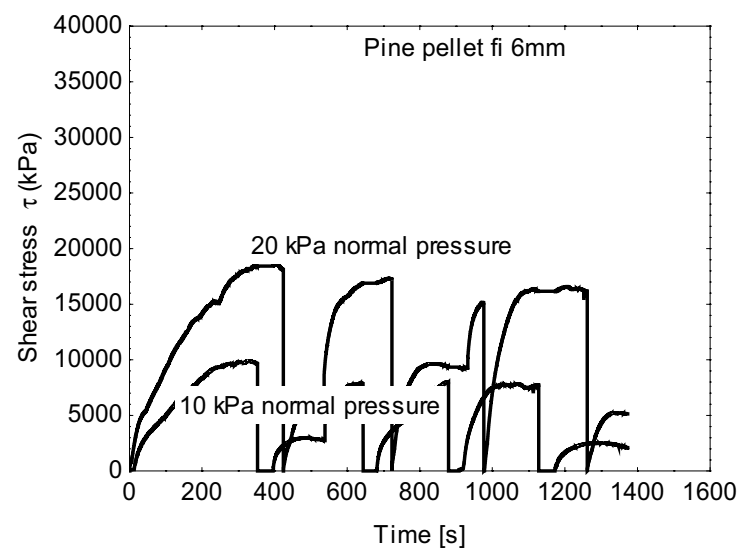

Fig. 5 Evolution of apparent shear stress with time for sawdust, shavings I and pellets obtained with ring shear tester

sawdust and shavings, described earlier as free flowing and free flowing material/cohesive materials, respectively, were characterised as cohesive materials here. No influence of the moisture content and normal stress on the ff was observed, which corroborated the results obtained with the Jenike shear tester. This is the reason that in the case of these materials, the internal structure and surface state of single particle are the decision parameter.

The effective angles of internal friction of the examined materials, obtained with the ring shear tester were observed to be higher than those determined with the Jenike tester. Regardless of the type of tester, the highest magnitudes of $\delta$ were obtained for pine shavings I. Using the Jenike shear tester, the parameter was measured to be $40^{\circ}$, while it was measured to be $56^{\circ}$ using the ring shear tester. For pine sawdust, $\delta$ obtained $\left(49^{\circ}\right)$ was higher than that obtained with the Jenike tester. A marginal influence of the moisture content on both $\phi$ and $\delta$ was observed. Moreover, no clear relation between these parameters and $\sigma_{\mathrm{n}}$ was observed, which corroborates the results obtained with the Jenike shear tester.

The last stage of the presented study comprised the experiments with the vane shear tester. The typical experimental results obtained with the vane shear tester for pine sawdust and pellets at $\sigma_{\mathrm{n}}$ of $5 \mathrm{kPa}$ and $30 \mathrm{kPa}$ and for rotational speeds of $3 \mathrm{rpm}$ and $13 \mathrm{rpm}$ are presented in Fig. 8. The evolution of the torque with time during shearing and relaxation after passing the first maximum value of $\tau$ are shown. After relaxation, the second maximum value of $\tau$ was obtained. The shape of the experimental curves differs with the material. The values of the maximum torque were observed to change with $\sigma_{\mathrm{n}}$. The torque-time curves were smoother for sawdust as compared to pellets, owing to the larger and nonregularly shaped particles composing the sawdust.

The relationships of first maximum torque $\left(T_{\max 1}\right)$, torque after first relaxation $\left(T_{\mathrm{R} 1}\right)$, second maximum torque $\left(T_{\max 2}\right)$ and second relaxation torque $\left(T_{\mathrm{R} 2}\right)$ with moisture content, $\sigma_{\mathrm{n}}$ and rotational speed were investigated in this study. The results of the experiments for the different moisture contents of sawdust and shavings, performed with vane shear tester, are presented in Fig. 9. The highest magnitudes of the torque were obtained for pine shavings II and pine pellets composed of large particles. This is a result of the internal structure of the samples, in which homogeneous particles of pellets also form strong structures under loads. The interlocking between single particles increased the strength of the sample against the vane rotating inside. In the case of pine pellets, $T_{\max 1}$ 
Table 3 Mechanical parameters of pine biomass, obtained in Jenike shear tester

\begin{tabular}{|c|c|c|c|c|c|c|}
\hline Material & $\begin{array}{l}\text { Moisture con- } \\
\text { tent }(\%)\end{array}$ & $\begin{array}{l}\text { Normal pres- } \\
\text { sure } \sigma_{\mathrm{n}} \\
(\mathrm{kPa})\end{array}$ & $\begin{array}{l}\text { Angle of internal } \\
\text { friction } \\
\phi \\
\left({ }^{\circ}\right)\end{array}$ & $\begin{array}{l}\text { Effective angle of } \\
\text { internal friction } \\
\delta \\
\left(^{\circ}\right)\end{array}$ & $\begin{array}{l}\text { Cohesion } \mathrm{C} \\
(\mathrm{kPa})\end{array}$ & $\begin{array}{l}\text { Flowability index } \\
\mathrm{i}\end{array}$ \\
\hline \multirow[t]{12}{*}{ Pine sawdust } & \multirow[t]{2}{*}{10} & 15 & $28.5 \pm 1.5$ & $34.0 \pm 1.7$ & $1.9 \pm 0.1$ & $0.2 \pm 0.1$ \\
\hline & & 30 & $23.8 \pm 1.5$ & $32.4 \pm 0.9$ & $5.5 \pm 0.2$ & $0.3 \pm 0.1$ \\
\hline & \multirow[t]{2}{*}{20} & 15 & $30.5 \pm 2.2$ & $36.3 \pm 0.5$ & $2.1 \pm 0.6$ & $0.2 \pm 0.1$ \\
\hline & & 30 & $32.2 \pm 2.1$ & $36.0 \pm 0.9$ & $2.8 \pm 0.8$ & $0.1 \pm 0.1$ \\
\hline & \multirow[t]{2}{*}{30} & 15 & $28.2 \pm 1.6$ & $35.7 \pm 0.3$ & $2.6 \pm 0.6$ & $0.3 \pm 0.0$ \\
\hline & & 30 & $28.4 \pm 2.2$ & $34.9 \pm 0.7$ & $4.5 \pm 1.0$ & $0.2 \pm 0.1$ \\
\hline & \multirow[t]{2}{*}{40} & 15 & $28.9 \pm 1.9$ & $35.6 \pm 0.2$ & $2.3 \pm 0.6$ & $0.2 \pm 0.0$ \\
\hline & & 30 & $29.3 \pm 2.9$ & $35.3 \pm 1.0$ & $4.2 \pm 1.1$ & $0.2 \pm 0.0$ \\
\hline & \multirow[t]{2}{*}{50} & 15 & $26.5 \pm 0.6$ & $34.7 \pm 0.4$ & $2.8 \pm 0.0$ & $0.3 \pm 0.1$ \\
\hline & & 30 & $28.9 \pm 1.6$ & $34.7 \pm 0.9$ & $4.1 \pm 0.4$ & $0.2 \pm 0.0$ \\
\hline & \multirow[t]{2}{*}{60} & 15 & $25.5 \pm 0.7$ & $33.8 \pm 0.4$ & $2.8 \pm 0.3$ & $0.3 \pm 0.0$ \\
\hline & & 30 & $24.8 \pm 1.7$ & $33.1 \pm 1.3$ & $5.4 \pm 0.3$ & $0.3 \pm 0.0$ \\
\hline \multirow[t]{12}{*}{ Pine shavings I } & \multirow[t]{2}{*}{10} & 15 & $28.9 \pm 2.6$ & $35.4 \pm 0.9$ & $2.3 \pm 0.5$ & $0.2 \pm 0.1$ \\
\hline & & 30 & $30.4 \pm 1.0$ & $35.6 \pm 0.8$ & $3.7 \pm 0.4$ & $0.2 \pm 0.0$ \\
\hline & \multirow[t]{2}{*}{20} & 15 & $36.6 \pm 2.9$ & $42.0 \pm 1.1$ & $2.2 \pm 0.7$ & $0.2 \pm 0.0$ \\
\hline & & 30 & $30.4 \pm 0.9$ & $39.8 \pm 0.7$ & $6.9 \pm 0.4$ & $0.3 \pm 0.1$ \\
\hline & \multirow[t]{2}{*}{30} & 15 & $39.4 \pm 0.8$ & $42.5 \pm 0.5$ & $1.4 \pm 0.1$ & $0.1 \pm 0.0$ \\
\hline & & 30 & $33.5 \pm 0.7$ & $40.2 \pm 0.4$ & $5.2 \pm 0.5$ & $0.3 \pm 0.1$ \\
\hline & \multirow[t]{2}{*}{40} & 15 & $39.0 \pm 0.5$ & $42.6 \pm 0.0$ & $1.6 \pm 0.2$ & $0.2 \pm 0.1$ \\
\hline & & 30 & $34.8 \pm 1.8$ & $41.5 \pm 1.0$ & $5.3 \pm 0.4$ & $0.3 \pm 0.0$ \\
\hline & \multirow[t]{2}{*}{50} & 15 & $37.3 \pm 0.7$ & $40.9 \pm 0.3$ & $1.5 \pm 0.4$ & $0.1 \pm 0.0$ \\
\hline & & 30 & $38.6 \pm 1.1$ & $40.3 \pm 0.7$ & $1.5 \pm 0.3$ & $0.1 \pm 0.0$ \\
\hline & \multirow[t]{2}{*}{60} & 15 & $34.3 \pm 1.0$ & $40.9 \pm 0.4$ & $2.7 \pm 0.4$ & $0.3 \pm 0.0$ \\
\hline & & 30 & $36.6 \pm 2.2$ & $40.5 \pm 0.4$ & $3.2 \pm 1.6$ & $0.2 \pm 0.0$ \\
\hline \multirow[t]{12}{*}{ Pine shavings II } & \multirow[t]{2}{*}{10} & 15 & $23.5 \pm 3.6$ & $36.8 \pm 1.1$ & $4.3 \pm 1.2$ & $0.4 \pm 0.1$ \\
\hline & & 30 & $26.9 \pm 3.4$ & $34.3 \pm 2.0$ & $5.0 \pm 1.5$ & $0.3 \pm 0.1$ \\
\hline & \multirow[t]{2}{*}{20} & 15 & $34.2 \pm 2.1$ & $42.1 \pm 0.8$ & $3.2 \pm 0.4$ & $0.3 \pm 0.0$ \\
\hline & & 30 & $28.6 \pm 0.8$ & $37.6 \pm 0.8$ & $6.3 \pm 0.3$ & $0.3 \pm 0.0$ \\
\hline & \multirow[t]{2}{*}{30} & 15 & $36.1 \pm 0.9$ & $40.5 \pm 0.4$ & $1.8 \pm 0.2$ & $0.2 \pm 0.0$ \\
\hline & & 30 & $34.0 \pm 2.5$ & $39.5 \pm 0.6$ & $4.2 \pm 1.5$ & $0.2 \pm 0.1$ \\
\hline & \multirow[t]{2}{*}{40} & 15 & $31.3 \pm 0.9$ & $44.9 \pm 0.5$ & $5.2 \pm 0.0$ & $0.5 \pm 0.0$ \\
\hline & & 30 & $28.1 \pm 3.0$ & $33.1 \pm 1.6$ & $3.4 \pm 0.8$ & $0.2 \pm 0.0$ \\
\hline & \multirow[t]{2}{*}{50} & 15 & $30.9 \pm 5.0$ & $42.5 \pm 0.5$ & $4.2 \pm 1.6$ & $0.4 \pm 0.1$ \\
\hline & & 30 & $30.7 \pm 1.3$ & $38.1 \pm 1.0$ & $5.4 \pm 0.4$ & $0.3 \pm 0.0$ \\
\hline & \multirow[t]{2}{*}{60} & 15 & $34.4 \pm 4.8$ & $41.3 \pm 2.7$ & $2.7 \pm 0.6$ & $0.3 \pm 0.1$ \\
\hline & & 30 & $25.9 \pm 4.0$ & $39.6 \pm 1.8$ & $9.2 \pm 1.7$ & $0.4 \pm 0.1$ \\
\hline \multirow[t]{2}{*}{ Pine pellets $\not 66 \mathrm{~mm}$} & \multirow[t]{2}{*}{10} & 15 & $30.2 \pm 5.0$ & $36.6 \pm 1.9$ & $2.3 \pm 1.0$ & $0.2 \pm 0.1$ \\
\hline & & 30 & $26.8 \pm 2.2$ & $33.8 \pm 1.4$ & $4.7 \pm 0.4$ & $0.2 \pm 0.1$ \\
\hline
\end{tabular}

was $24 \mathrm{Nm}$ at the maximum $\sigma_{\mathrm{n}}$. For pine shavings, $T_{\max 1}$ was approximately $20 \mathrm{Nm}$. The magnitudes of the torque for pine shavings I was approximately three times smaller than those for shavings II and pellets. Moreover, the magnitudes of the torque for sawdust were approximately $50 \%$ smaller than those obtained for pellets and shavings II.

For all the examined materials, $T_{\max }$ and $T_{\mathrm{R}}$ increased with an increase in the moisture content from 10 to $60 \%$, and with an increase in the normal pressure $\sigma_{\mathrm{n}}$ from 5 to $30 \mathrm{kPa}$. No significant influence of the rotation speed on the torques was observed. The factor that exerted the strongest influence on the torques was moisture content. The results verified that the moisture content significantly influenced the mechanical strength of the granular biomass. The strongest influence of the moisture content on the torques was observed for shavings, while the effect was weaker for pine sawdust. 
Table 4 Mechanical parameters of pine biomass, obtained in ring shear tester

\begin{tabular}{|c|c|c|c|c|c|}
\hline Material & $\begin{array}{l}\text { Moisture } \\
\text { content }(\%)\end{array}$ & $\begin{array}{l}\text { Normal } \\
\text { pressure } \\
\sigma_{\mathrm{n}} \\
(\mathrm{kPa})\end{array}$ & $\begin{array}{l}\text { Flow factor } \\
\text { ff }\end{array}$ & $\begin{array}{l}\text { Effective angle of } \\
\text { internal friction } \\
\delta \\
\left({ }^{\circ}\right)\end{array}$ & $\begin{array}{l}\text { Angle of } \\
\text { internal fric- } \\
\text { tion } \\
\phi \\
\left(^{\circ}\right)\end{array}$ \\
\hline \multirow[t]{12}{*}{ Pine sawdust } & \multirow[t]{2}{*}{10} & 10 & $4.1 \pm 0.4$ & $48.6 \pm 0.4$ & $42.9 \pm 0.9$ \\
\hline & & 20 & $3.6 \pm 0.2$ & $48.8 \pm 0.7$ & $42.3 \pm 0.8$ \\
\hline & \multirow[t]{2}{*}{20} & 10 & $3.6 \pm 0.2$ & $49.3 \pm 1.3$ & $42.7 \pm 1.1$ \\
\hline & & 20 & $3.1 \pm 0.1$ & $50.1 \pm 0.4$ & $42.5 \pm 0.5$ \\
\hline & \multirow[t]{2}{*}{30} & 10 & $3.7 \pm 0.2$ & $49.0 \pm 0.3$ & $42.7 \pm 0.5$ \\
\hline & & 20 & $3.6 \pm 0.5$ & $49.5 \pm 0.6$ & $42.9 \pm 0.5$ \\
\hline & \multirow[t]{2}{*}{40} & 10 & $3.4 \pm 0.1$ & $49.7 \pm 1.2$ & $42.8 \pm 1.1$ \\
\hline & & 20 & $3.4 \pm 0.4$ & $49.0 \pm 1.4$ & $42.0 \pm 1.5$ \\
\hline & \multirow[t]{2}{*}{50} & 10 & $3.7 \pm 0.3$ & $48.1 \pm 0.5$ & $41.7 \pm 1.2$ \\
\hline & & 20 & $3.2 \pm 0.1$ & $49.7 \pm 1.6$ & $42.2 \pm 1.6$ \\
\hline & \multirow[t]{2}{*}{60} & 10 & $3.5 \pm 0.4$ & $49.7 \pm 1.0$ & $42.8 \pm 0.7$ \\
\hline & & 20 & $3.5 \pm 0.3$ & $49.4 \pm 0.5$ & $42.6 \pm 1.2$ \\
\hline \multirow[t]{12}{*}{ Pine shavings I } & \multirow[t]{2}{*}{10} & 10 & $3.4 \pm 0.4$ & $52.9 \pm 1.4$ & $46.4 \pm 1.3$ \\
\hline & & 20 & $3.1 \pm 1.0$ & $59.5 \pm 7.7$ & $52.6 \pm 8.4$ \\
\hline & \multirow[t]{2}{*}{20} & 10 & $2.7 \pm 0.2$ & $57.0 \pm 4.8$ & $49.0 \pm 5.0$ \\
\hline & & 20 & $2.6 \pm 0.1$ & $56.6 \pm 0.4$ & $48.2 \pm 0.1$ \\
\hline & \multirow[t]{2}{*}{30} & 10 & $3.8 \pm 0.7$ & $49.4 \pm 0.5$ & $43.0 \pm 1.6$ \\
\hline & & 20 & $3.7 \pm 0.5$ & $52.3 \pm 1.2$ & $46.6 \pm 2.5$ \\
\hline & \multirow[t]{2}{*}{40} & 10 & $3.3 \pm 0.5$ & $52.5 \pm 0.5$ & $47.2 \pm 0.2$ \\
\hline & & 20 & $3.1 \pm 0.0$ & $53.3 \pm 1.2$ & $46.7 \pm 1.5$ \\
\hline & \multirow[t]{2}{*}{50} & 10 & $3.8 \pm 0.3$ & $52.2 \pm 0.8$ & $47.3 \pm 0.3$ \\
\hline & & 20 & $3.5 \pm 0.2$ & $52.8 \pm 2.4$ & $47.4 \pm 2.7$ \\
\hline & \multirow[t]{2}{*}{60} & 10 & $3.4 \pm 0.3$ & $53.7 \pm 1.8$ & $46.7 \pm 1.5$ \\
\hline & & 20 & $3.7 \pm 0.2$ & $53.1 \pm 0.8$ & $45.4 \pm 0.1$ \\
\hline \multirow{2}{*}{$\begin{array}{l}\text { Pine pellets } \\
\phi 6 \mathrm{~mm}\end{array}$} & \multirow[t]{2}{*}{10} & 10 & $30.2 \pm 2.9$ & $41.7 \pm 1.8$ & $41.3 \pm 2.3$ \\
\hline & & 20 & $8.0 \pm 0.9$ & $42.8 \pm 0.3$ & $39.9 \pm 0.1$ \\
\hline
\end{tabular}

No results were obtained for pine shavings II due to too long particles of the material
The normal pressure $\left(\sigma_{\mathrm{n}}\right)$ significantly affected the torques in sawdust, while no influence was observed for shavings and pellets.

No influence of the rotational speed of the vane on the torque was observed for the tester. The relaxation after the asymptotic value following the first stoppage of the vane decreased to $T_{\mathrm{R} 1}$ magnitudes. The magnitude of torque after the first maximum value $\left(T_{\max 1}\right)$ decreased to an asymptotic value. For sawdust and shavings I, $T_{\mathrm{R} 1}$ was smaller by approximately $30 \%$, while for shavings II, it was smaller by $25 \%$. A maximum decrease in $T_{\mathrm{R} 1}$, by approximately $33 \%$, was obtained for pellets. This probably results from a reorganisation of the pellet particles, which could slide against each other during the relaxation process.

Moreover, in the case of the decrease in the torque magnitude after the attainment of the second maximum $\left(T_{\max 2}\right)$, $T_{\mathrm{R} 2}$ decreased by approximately $30 \%$ for sawdust and shavings and by $40 \%$ for pellets. For all the materials, $T_{\max 2}$ was approximately $20 \%$ smaller than $T_{\max 1}$.

\section{Discussion}

The paper presented the results of experiments performed on typical biomass materials which are used in several technologies in many branches. Pine granular products are highly popular; therefore, it is necessary to determine their mechanical parameters.

In this study, the standard Jenike shear tester and Schulze ring shear tester were used to determine the strength and flowability of pine biomass. The obtained results demonstrated that materials comprising larger particles exhibited more complex behaviour with bridging tendency. These results corroborated the observations of Mattsson and Kofman (2003), who reported that the proportion of long particles is the crucial factor for explaining the tendency to bridge.

The densities determined for the experimental materials did not verify the observations of Littlefield et al. (2011), who observed that the density of pecan shells decreased 


\section{(a) Angle of internal friction $\varphi$}
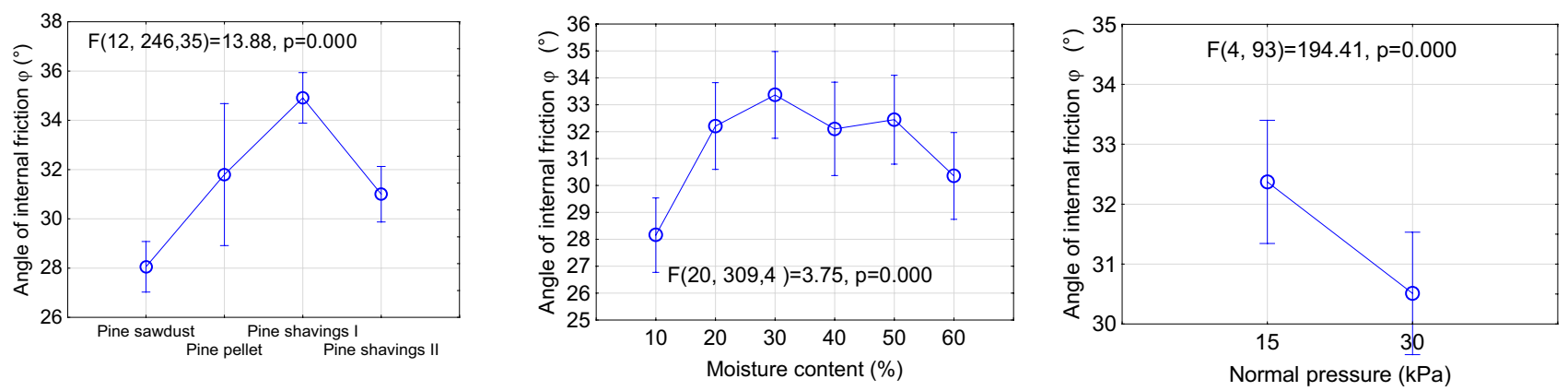

(b) Effective angle of internal friction $\delta$
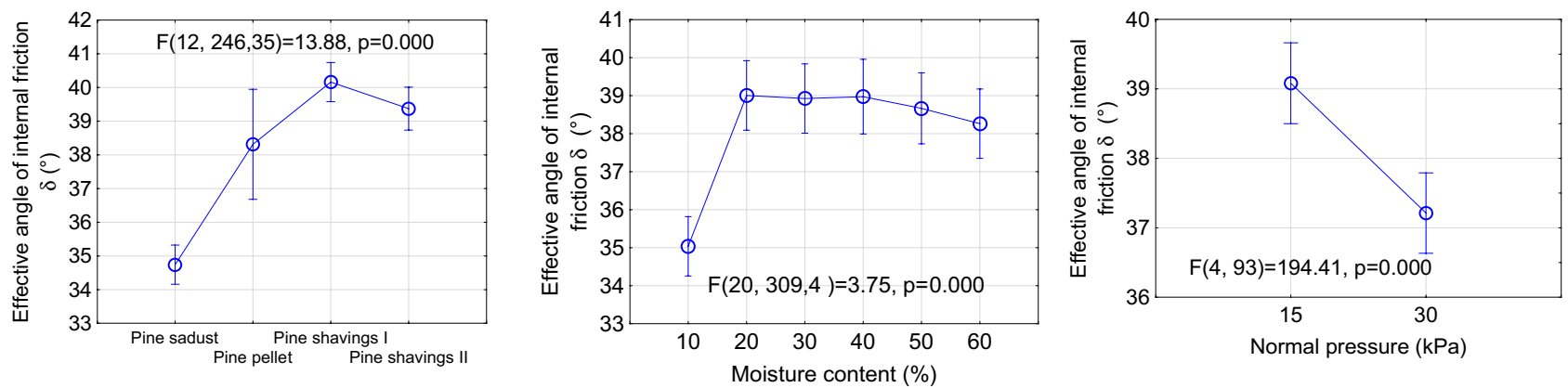

(c) Flowability index i
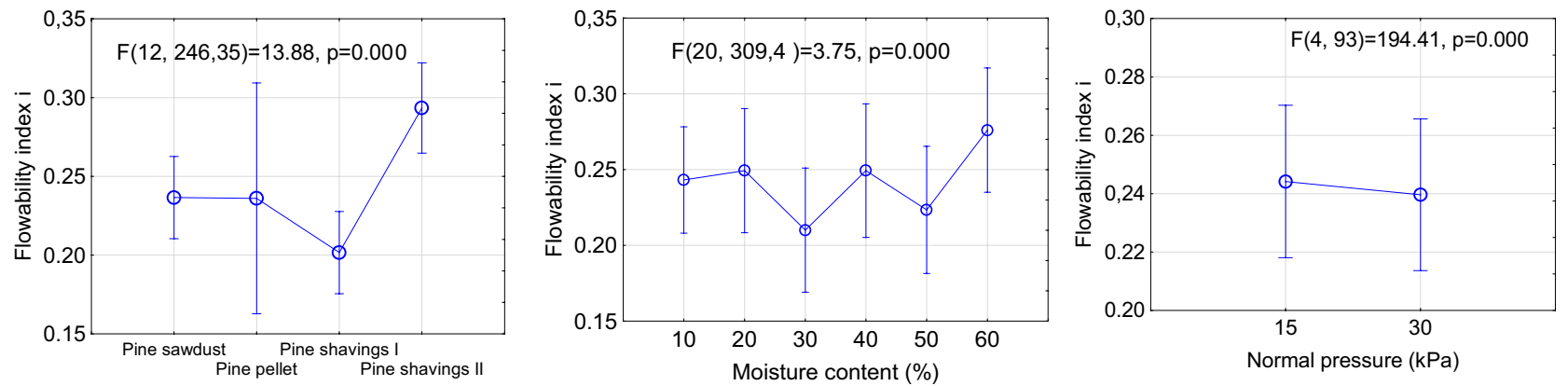

(d) Cohesion $\mathrm{C}$
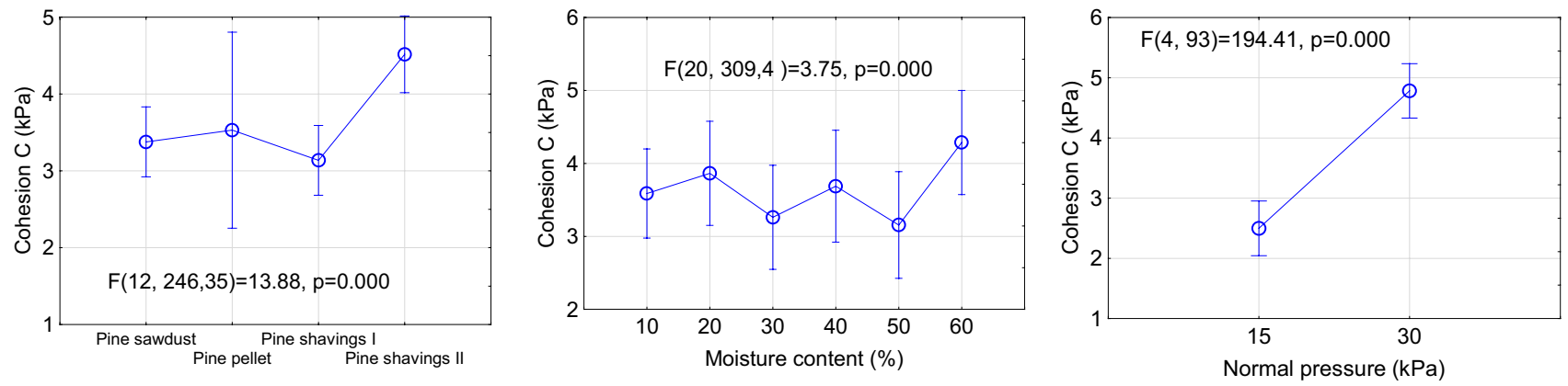

Fig. 6 Mean values and 95\% confidence intervals of mechanical parameters of materials for different moisture contents and normal pressures, obtained in Jenike shear tester 
(a) Flow factor ff
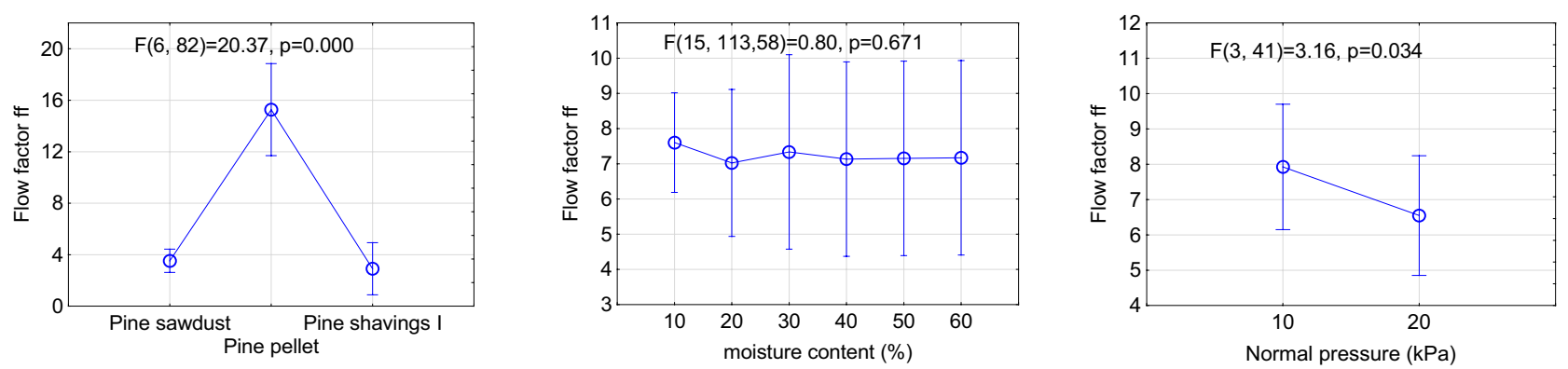

(b) Effective angle of internal friction $\delta$
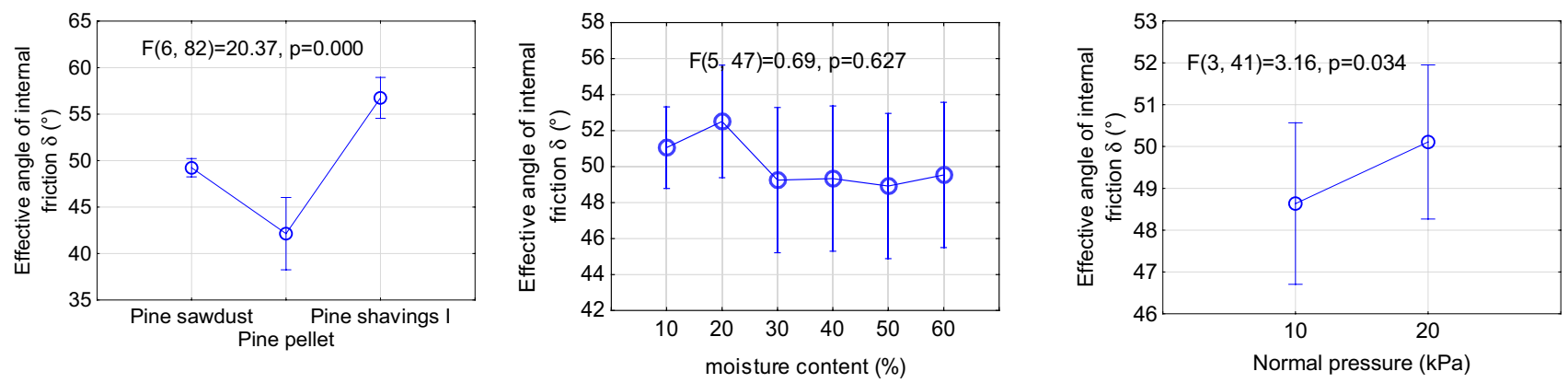

(c) Angle of internal friction $\varphi$
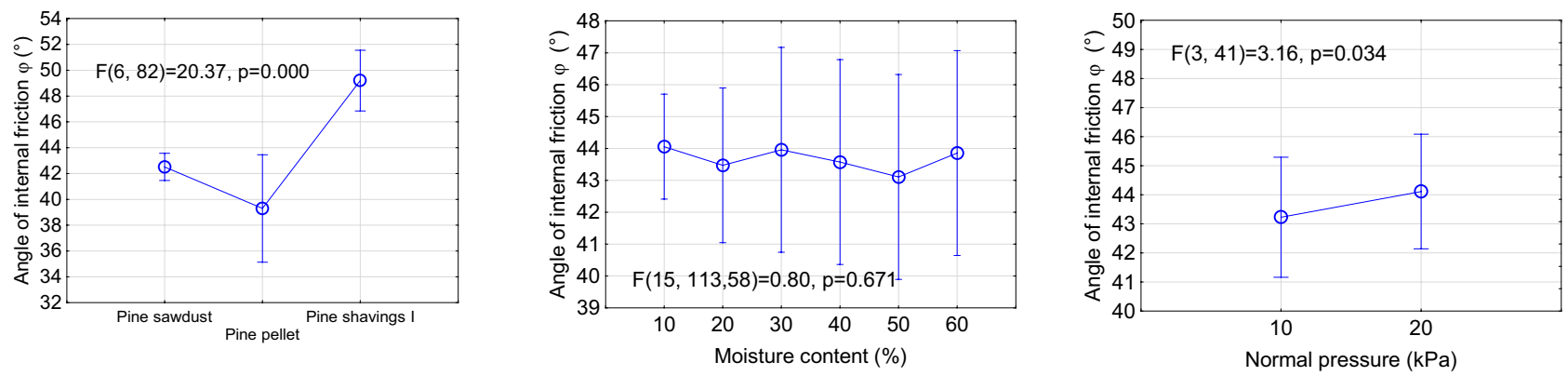

Fig. 7 Mean values and 95\% confidence intervals of flow factor, angle of internal friction and effective angle of internal friction for different moisture contents and normal pressures, obtained with ring shear tester

significantly when the particle size increased. In this study, the maximum density was obtained for pine sawdust. A very high density of pellets resulted from the densification of the raw material during pellet production. The density of the material was observed to increase when the moisture content increased, which corroborated observations reported by Stasiak et al. (2015) for birch sawdust and poplar woodchips and is not surprising. The magnitudes of the angle of internal friction $(\phi)$ determined for sawdust with the Jenike shear tester were similar to those measured by Gil et al. (2013) for milled poplar. However, the effect of the particle size on the angles of internal friction observed by these authors was not completely similar to the results obtained in this study which is probably the effect of more elastic particles of experimental materials examined by the authors.
For all the materials, the magnitudes of $\delta$ obtained in the ring shear tester were higher than those determined by using the Jenike shear tester. For typical cases of design, higher values of this parameter give safer construction paths, and rather values obtained in ring shear tester should be used. Higher values obtained in the case of the ring tester are the result of an unlimited shear path which is limited in the case of Jenike's tester. The magnitudes of the parameters determined with the ring shear tester were similar to those obtained by Miccio et al. (2013) for sawdust and olive husk; however, the magnitudes for pine biomass were higher than those for sawdust and olive husk. These discrepancies in results were owing to the lower normal stress in the experiments conducted by Miccio et al. (2013). The magnitudes of the angle of internal friction for pine pellets determined 


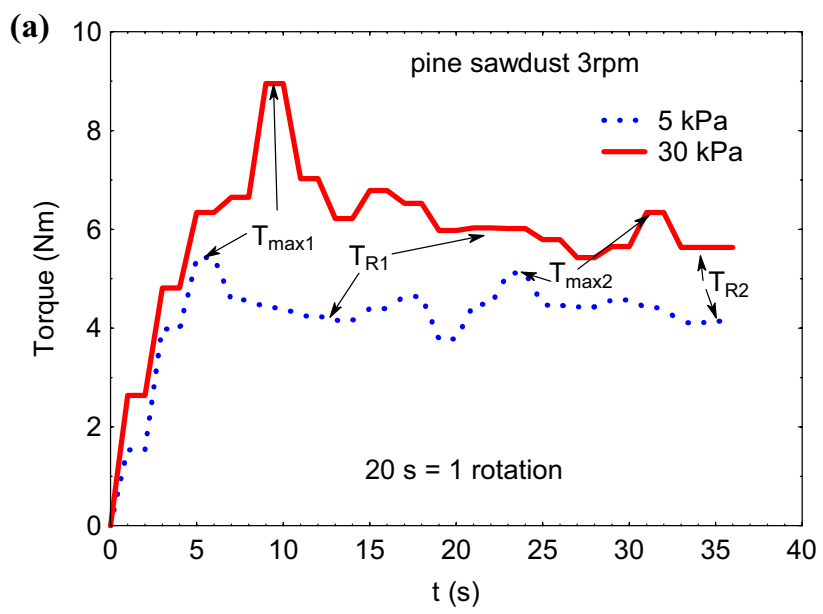

(c)

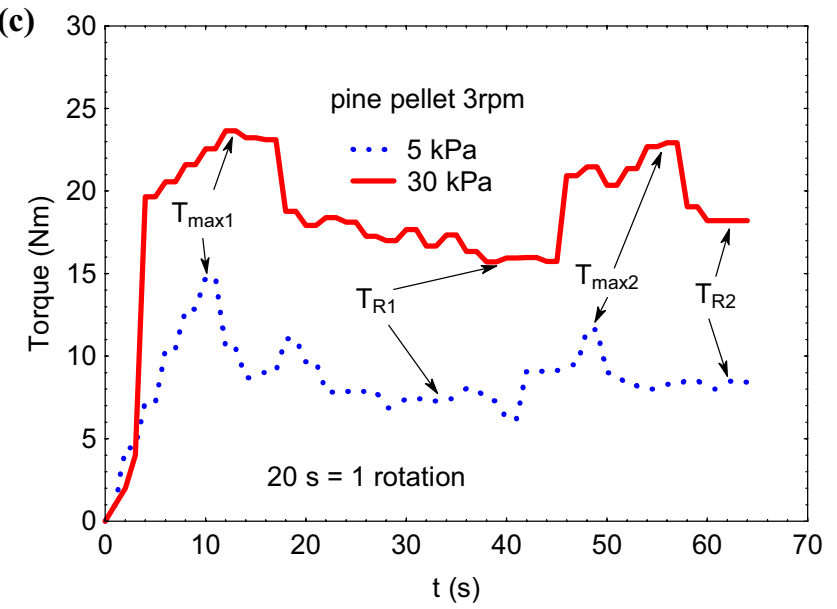

Fig. 8 Typical torque-time curves obtained at normal pressures of $5 \mathrm{kPa}$ and $30 \mathrm{kPa}$ for rotational speed of 3 and $13 \mathrm{rpm}$ for sawdust $(\mathbf{a}, \mathbf{b})$ and pellets $(\mathbf{c}, \mathbf{d})$, obtained in vane shear tester. First maximum

using the ring shear tester were approximately equal to those obtained by Wu et al. (2011) for wood pellets, which results from the fact that pellet is a densified product and it is less important from what type of wood it is made. The magnitudes of the angle of internal friction measured with the ring shear tester for sawdust were similar to those obtained by Barletta and Poletto (2013) for wood powder. This is the reason for close particle size distribution of these two materials and shows the effect of properly selected laboratory testers.

The new vane tester, previously used for determining the properties of woodchips by Stasiak et al. (2018), was used in this study to determine the torque magnitudes of pine biomass with various particle size distributions. A review of the literature has revealed that the vane shear tester has not been used for investigating various types of pine biomass until the present. The vane tester is a common and standardised device used for determining soil mechanical properties (ASTM D2573-72 1972). The knowledge of these parameters could aid in the validation of the loads produced
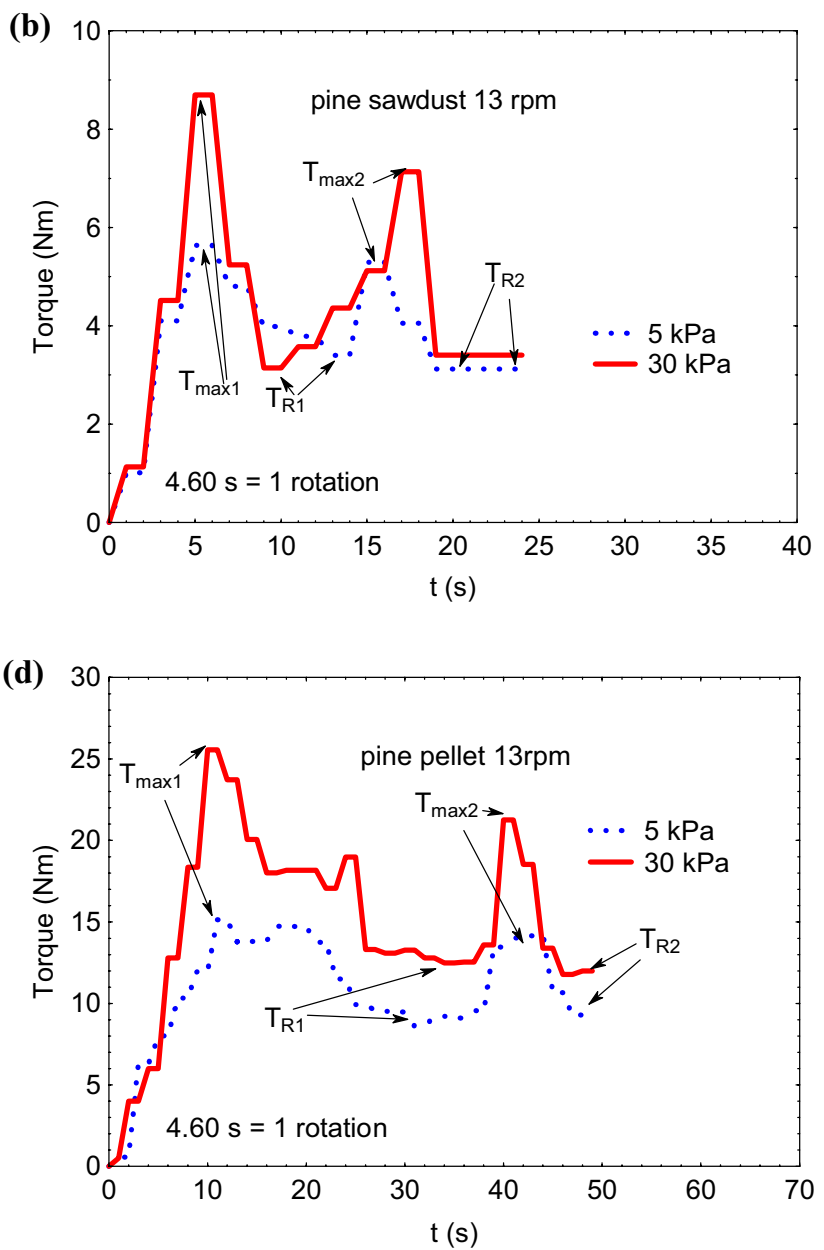

torque $\left(T_{\max 1}\right)$, torque after first relaxation $\left(T_{\mathrm{R} 1}\right)$, second maximum torque $\left(T_{\max 2}\right)$, second relaxation torque $\left(T_{\mathrm{R} 2}\right)$

during the emptying of the chamber with screw feeder and also in the process of pellet production.

The $\tau$ experimental results differed from each other and were strongly affected by the differences in the size and shape of single particles of the experimental material. The comparison between the magnitudes of torque determined with the vane tester for pine materials and those previously measured by Stasiak et al. (2018) for woodchips has demonstrated that the magnitudes of the parameter were smaller by even $200 \%$ for pine materials, what is the effect of size and shape of single particles of this material. Regardless of the material, no influence of the rotational speed on the torque was observed.

With the increasing interest in granular biomass and the scale of its application, there is a need to develop new devices and test procedures to determine its characteristics.

The method based on the vane shearing was developed for rheological examinations of various materials (Barnes and Nguyen 2001). The method has also been used by Samaniuk 


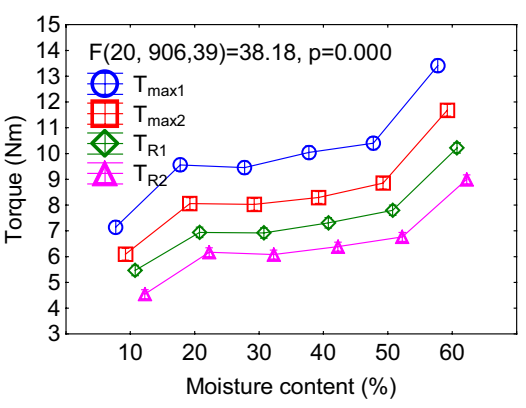

sawdust
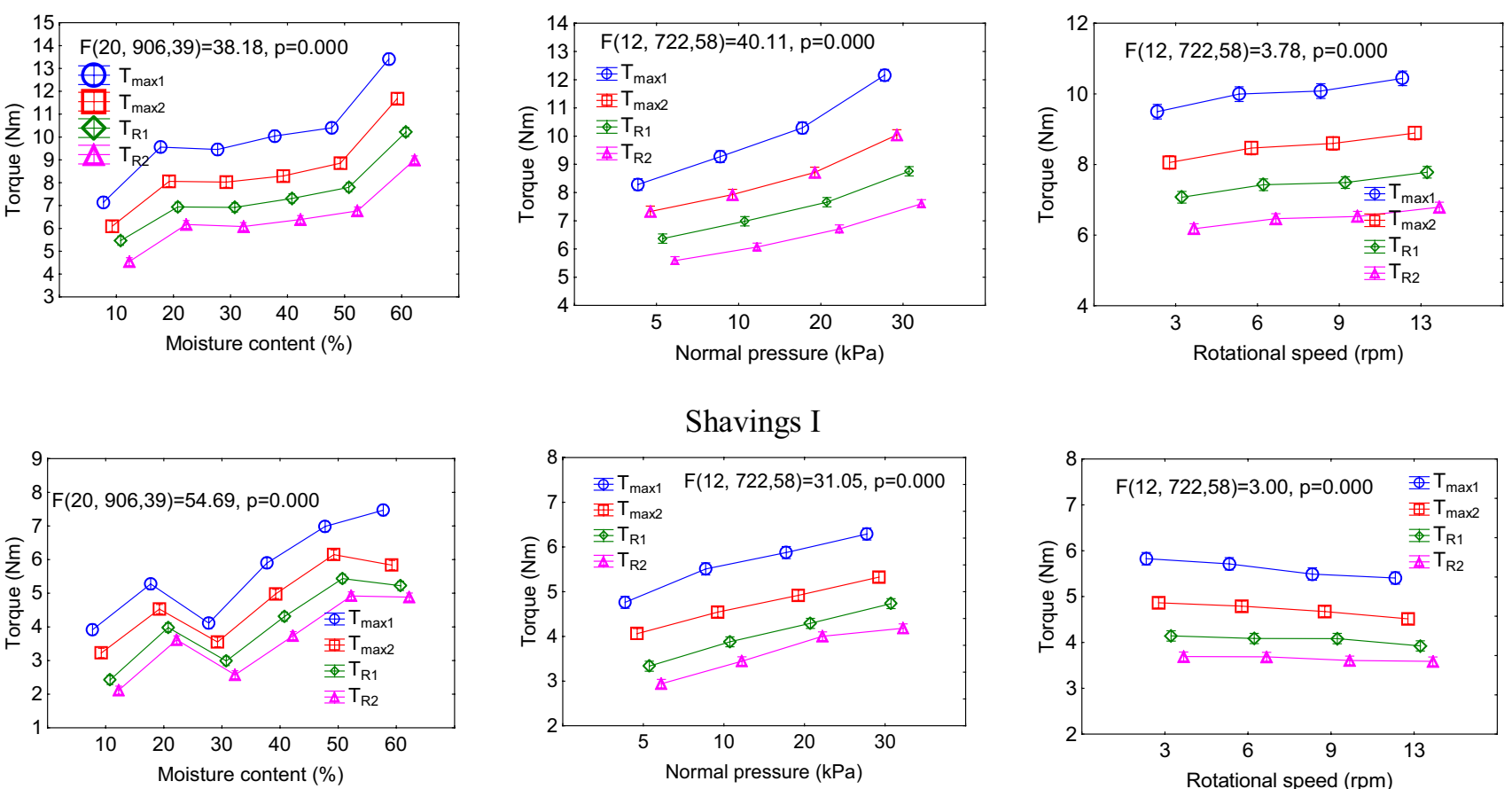

Shavings I
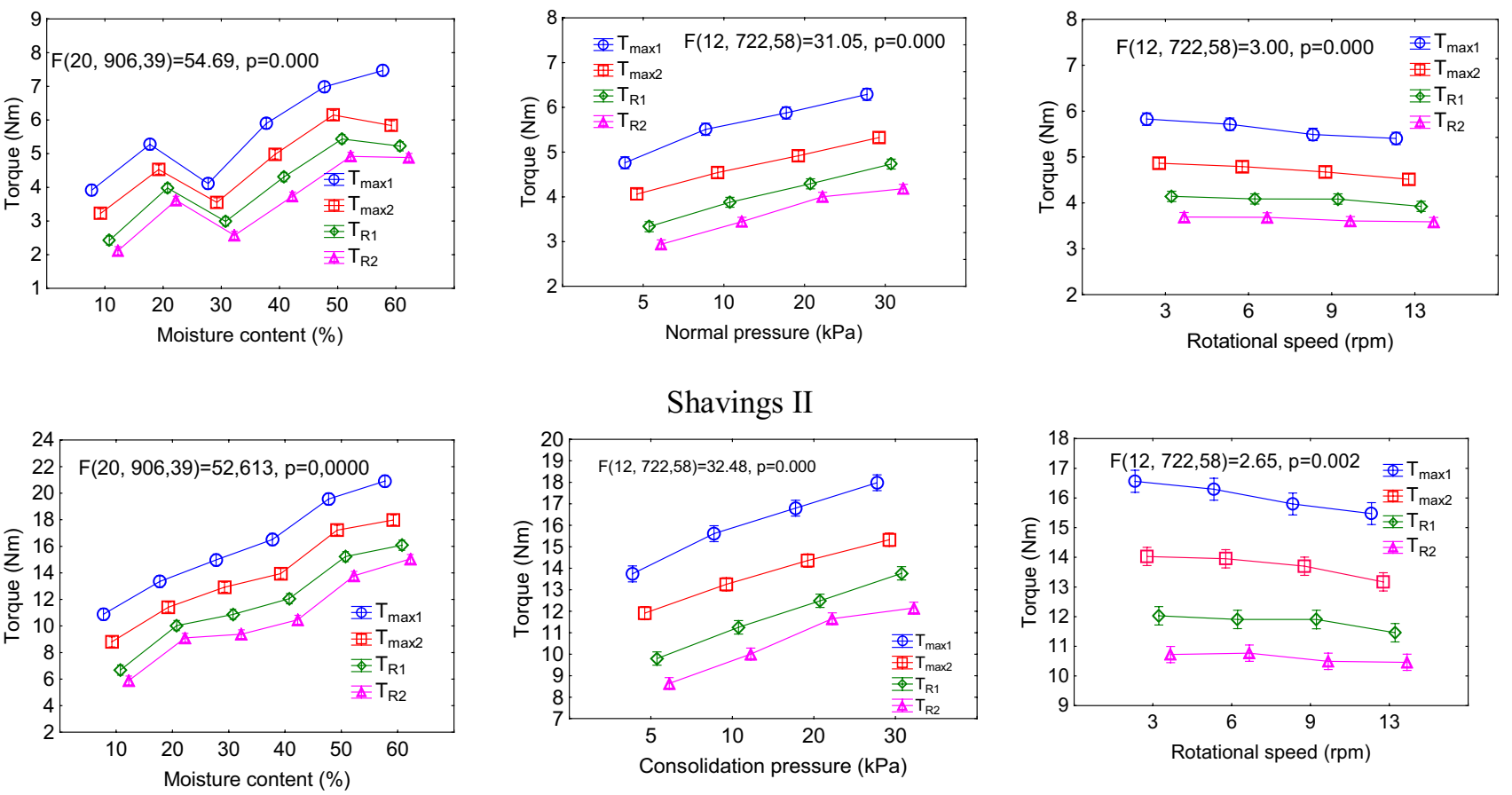

Pellets
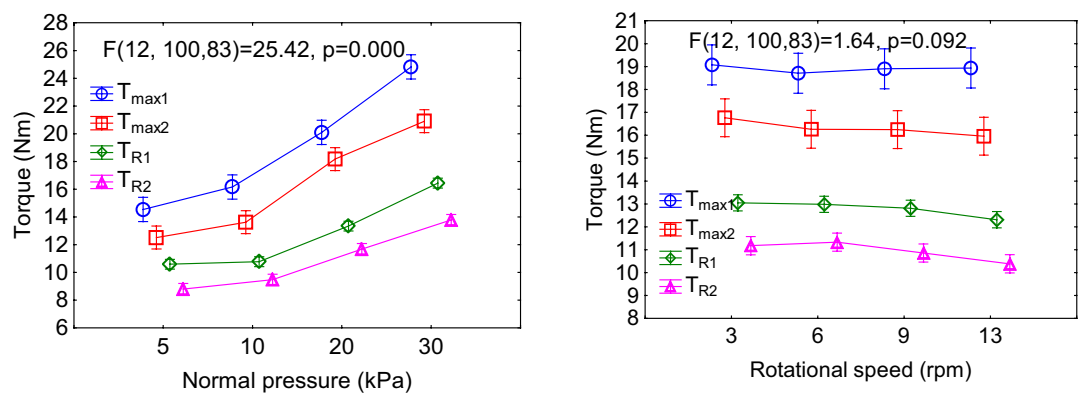

Fig. 9 Mean values and 95\% confidence intervals of torque for experimental materials for different moisture contents, normal pressures and rotational speeds. First maximum torque $\left(T_{\max 1}\right)$, torque after first relaxation $\left(T_{\mathrm{R} 1}\right)$, second maximum torque $\left(T_{\max 2}\right)$, second relaxation torque $\left(T_{\mathrm{R} 2}\right)$

et al. (2011) for concentrated biomass and for modified lignocellulosic biomass suspension by Samaniuk et al. (2015), as well as by Amiri et al. (2012) for biomass of animal origin such as cow manure. The experimental results presented in this paper are comparable with data obtained by Samaniuk et al. $(2011,2015)$ for milled corn stover, and the magnitudes of the measured parameters are higher than those obtained by Amiri et al. (2012) for cow manure. In both the cases, the authors reported a strong influence of the rotational speed on the torque, what contradicted the results obtained in this 
study. This is probably a result of the higher water content of the manure, causing it to behave like a viscous material, i.e., with shear strength dependent on shear velocity. However, the results of this study are consistent with those presented by Stasiak et al. (2018) for woodchips.

\section{Conclusion}

Mechanical parameters of four types of pine granular biomass at different moisture contents were determined. The results obtained revealed distinct differences between the mechanical parameters of the experimental materials, which indicated that these materials require different adjustments and operations in the technological process. Strength and flowability parameters are affected by normal pressure which, in consequence, may lead to stop of flow and result in a need for different designs of required installation.

The highest values of the bulk and tapped densities were obtained for pellets, whereas the lowest densities were obtained for shavings. The density of the material was also observed to be affected by the moisture content, time of compression and normal pressure $\sigma_{\mathrm{n}}$.

No influence of the moisture content on the maximum value of $\tau$ was observed. The moisture content also did not significantly influence the flowability index.

The highest $\mathrm{C}$ was obtained for shavings II, while it was at a similar level for the other materials. Cohesion $C$ was observed to be not influenced by the moisture content, while a strong influence of $\sigma_{\mathrm{n}}$ on the magnitude of the parameter was observed.

The magnitudes of apparent shear stress $\tau$ obtained with the ring shear tester were comparable with those obtained with the Jenike shear tester, and the maximum $\tau$ was influenced by the moisture content and normal stress.

No influence of the moisture content on the results obtained in Jenike shear tester was observed.

For all the materials, the magnitudes of $\delta$ obtained in the ring shear tester were higher than those determined by using the Jenike shear tester. An increase in $\sigma_{\mathrm{n}}$ resulted in an increase in $\delta$.

No influence of the moisture content on $\phi$ was noted, only a slight increase was observed in the magnitude of the parameter when $\sigma_{\mathrm{n}}$ increased.

The maximum values of the torque obtained in vane shear tester also differed for different normal pressures and moisture contents. The highest values of torque were obtained for pine shavings II and pine pellets, composed of the largest particles. For all the materials, the magnitudes of the torques $T_{\max }$ and $T_{\mathrm{R}}$ increased with an increase in the moisture content from and in $\sigma_{\mathrm{n}}$.

No significant influence of the rotation speed on the magnitudes of the torque was observed; however, a strong effect of the moisture content on the magnitudes of the parameters was observed.

The vane shear tester was found to be a useful tool for comparing the properties of granular biomass differing in particle size distributions.

Acknowledgements Research financed by The National Centre for Research and Development, Poland in the frame of the Project PBS3/ A8/31/2015.

\section{Compliance with ethical standards}

Conflict of interest On behalf of all authors, the corresponding author states that there is no conflict of interest.

Open Access This article is distributed under the terms of the Creative Commons Attribution 4.0 International License (http://creativeco mmons.org/licenses/by/4.0/), which permits unrestricted use, distribution, and reproduction in any medium, provided you give appropriate credit to the original author(s) and the source, provide a link to the Creative Commons license, and indicate if changes were made.

\section{References}

Amiri H, Arabhesseini A, Kianmehr MH (2012) Design, construction and evaluation of shear vane device for biomass yield stress determination. Agric Eng CIGR J 14(4):188-194

ASTM D2573-72 (1972) Standard test method for field vane shear test in cohesive soil. American Society for Testing and Materials, Philadelphia

ASTM D6128-06 (2006) Standard test method for shear testing of bulk solids using the Jenike shear cell. American Society for Testing and Materials, Philadelphia

ASTM D6773-02 (2002) Standard shear test method for bulk solids using the Schulze ring shear tester. American Society for Testing and Materials, Philadelphia

Ayuga F, Aguado P, Gallego E, Ramírez A (2005) New steps towards the knowledge of silos behaviour. Int Agrophys 19(1):7-17

Barletta D, Poletto M (2013) An assessment on silo design procedures for granular woody biomass. Chem Eng Trans 32:2209-2214

Barnes HA, Nguyen Q (2001) Rotating vane rheometry-a review. J Non-Newton Fliud Mech 98:1-14

Barois-Cazanave A, Marchal P, Falk V, Choplin L (1999) Experimental study of powder rheological behaviour. Powder Technol 103:58-64

Crawford NC, Nagle N, Sievers DA, Stickel JJ (2016) The effect of physical and chemical preprocessing on the flowability of corn stover. Biomass Bioenerg 85:126-134

Dai J, Grace JR (2011) Biomass granular screw feeding: an experimental investigation. Biomass Bioenerg 35:942-955

Eurocode 1 (2006) Part 4: Basis of design and actions on structures. Actions in silos and tanks. European Committee for Standardization, Amsterdam

Ganesan V, Rosentrater KA, Muthukumarappan K (2008) Flowability and handling characteristics of bulk solids and powders-a review with implications for DDGS. Biosyst Eng 101:425-435

Gil M, Schott D, Arauzo I, Teruel E (2013) Handling behavior of two milled biomass: SRF poplar and corn stover. Fuel Process Technol 112:76-85

Ileleji KE, Zhou B (2008) The angle of repose of bulk corn stover particles. Powder Technol 187:110-118 
Kamath S, Puri VM, Manbeck HB (1994) Flow property measurement using the Jenike cell for wheat flour at various moisture contents and consolidation times. Powder Technol 81:293-297

Littlefield B, Fasina OO, Shaw J, Adhikari S, Via B (2011) Physical and flow properties of pecan shells-particle size and moisture effect. Powder Technol 212:173-180

Mattsson JE, Kofman PD (2003) Influence of particle size and moisture content on tendency to bridge in biofuels made from willow shoots. Biomass Bioenerg 24:429-435

Miccio F, Silvestri N, Barletta D, Poletto M (2011) Characterization of woody biomass flowability. Chem Eng Trans 24:643-648

Miccio F, Barletta D, Poletto M (2013) Flow properties and arching behavior of biomass particulate solids. Powder Technol 235:312-321

Molenda M, Stasiak M, Moya M, Ramirez A, Horabik J, Ayuga F (2006) Testing mechanical properties of food powders in two laboratories-degree of consistency of results. Int Agrophys 20(1):37-45

Nyström J, Dahlquist E (2004) Methods for determination of moisture content in woodchips for power plants-a review. Fuel 83:773-779

Oniszczuk T, Pilawka R, Oniszczuk A (2013) Influence of grounded pine bark addition on mechanical strength of thermoplastic starch. Chem Ind 92(8):1554-1558

Oniszczuk T, Mitrus M, Wójtowicz A, Mościcki L (2015) Addition of bark in the production of the starch-based composites. Chem Ind 94(10): 1748-1751

Oniszczuk T, Wójtowicz A, Mościcki L, Mitrus M, Kupryaniuk K, Kusz A, Bartnik G (2016) Effect of natural fibres on the mechanical properties of thermoplastic starch. Int Agrophys 30(2):211-218

Samaniuk JR, Wang J, Root W, Scott CT, Klingenberg DJ (2011) Rheology of concentrated biomass. Korea Aust Rheol J 23(4):237-245

Samaniuk JR, Scott CT, Root WT, Klingenberg DJ (2015) Effects of process variables on the yield stress of rheologically modified biomass. Rheol Acta 54:941-949
Saw HY, Davies CE, Paterson AHJ, Jones JR (2015) Correlation between powder flow properties measured by shear testing and Hausner ratio. Procedia Eng 102:218-225

Schulze D (2008) Powders and bulk solids: behaviour, characterization, storage and flow. Springer, Berlin

Schwedes J, Schulze D (1990) Measurement of flow properties of bulk solids. Powder Technol 61:59-68

Spinelli R, Nati C, Sozzi L, Magagnotti N, Picchi G (2011) Physical characterization of commercial woodchips on the Italian energy market. Fuel 90:2198-2202

Stasiak M, Skiba K, Molenda M, Tys J, Mościcki L (2012) The mechanical parameters of rapeseed cake. Energy Sour Part A Recovery Util Environ Eff 34(13):1196-1205

Stasiak M, Molenda M, Opaliński I, Błaszczak W (2013) Mechanical properties of native corn, wheat and potato starches. Czech J Food Sci 31(4):347-354

Stasiak M, Molenda M, Bańda M, Gondek E (2015) Mechanical properties of sawdust and woodchips. Fuel 159:900-908

Stasiak M, Molenda M, Gancarz M, Wiącek J, Parafiniuk P, Lisowski A (2018) Characterization of shear behaviour in consolidated granular biomass. Powder Technol 327:120-127

US Patent 4.181.023 (1980) Apparatus for short-duration tests for determining the flowability of powders. United States Patents and Trademark Office

Wu MR, Schott DL, Lodewijks G (2011) Physical properties of solid biomass. Biomass Bioenerg 35:2093-2105

Zulfigar M, Moghtaderi B, Wall TF (2006) Flow properties of biomass and coal blends. Fuel Process Technol 87:281-288

Publisher's Note Springer Nature remains neutral with regard to jurisdictional claims in published maps and institutional affiliations. 